\title{
Evaluation of Bovine Spongiform Encephalopathy (BSE) Infection Risk of Cattle via Sewage Sludge from Wastewater Treatment Facilities in Slaughterhouses in Japan
}

\author{
Takehisa YAMAMOTO ${ }^{1)}$, Sota KOBAYASHI ${ }^{1)}$, Akiko NISHIGUCHI ${ }^{1)}$, Takashi NONAKA ${ }^{1)}$ and Toshiyuki TSUTSUI ${ }^{1) *}$ \\ 1) Applied Epidemiology Section, National Institute of Animal Health, 3-1-5, Kannondai, Tsukuba-shi, Ibaraki-ken, 305-0856, Japan
}

(Received 21 July 2005/Accepted 24 October 2005)

\begin{abstract}
Scattered SRM residues from BSE-infected cattle are possible to contaminate sewage during the slaughtering process in slaughterhouses. A proportion of the sludge discharged from wastewater treatment facilities at slaughterhouses has historically been processed into fertilizer. We therefore investigated the associated risk of BSE infection to cattle via sludge-derived fertilizer. Each stage of the process associated with BSE exposure was qualitatively evaluated and quantitative evaluations were subsequently performed using infectious dose as a unit of concern. Results of these qualitative evaluations indicated that installation of filter(s) at the drains to the wastewater treatment facilities has been undertaken by many slaughterhouses and has decreased the likelihood of SRM contamination of sewage. The level of sludge-derived fertilizer ingested by cattle was considered to be very low since the fertilizer is mixed with the ground soil, and the amount of soil ingested by cattle is likely to be small. Results from the quantitative analysis indicated the total infectious dose ingested by cattle in Japan from an infected cow has been estimated to be $5.5 \times 10^{-3} \mathrm{ID}_{50}$. Preventing scattering of SRM during the slaughtering process, installing filters to the drains with the removal of residues from the drain water and preventing the application of sludge-derived fertilizer to pasturelands would be effective to reduce the risk. Although the limited extent of available information, this study should provide useful indication for the development of an inclusive risk assessment for slaughterhouse sludge in the future.
\end{abstract}

KEY WORDS: abattoir, Bovine Spongiform Encephalopathy (BSE), fertilizer, risk assessment, sewage sludge.

J. Vet. Med. Sci. 68(2): 137-142, 2006

Bovine Spongiform Encephalopathy (BSE), an infectious, neurodegenerative, fatal brain disease of cattle, was first found in the United Kingdom in 1986 and its occurrence has subsequently been confirmed mainly in European nations. Since BSE is suspected of being the link to a new variant of Creutzfeldt-Jakob Disease in humans, it has become a grave public health concern. The source of BSE infection is believed to be an abnormal form of prion protein that accumulates in the central nervous system in BSEinfected cattle [5]. The main BSE infection route is thought to be cattle meat and bone meal (MBM) containing prion proteins from BSE infected cattle [6]. Therefore, as part of BSE risk management, the use of MBM for cattle feed has been prohibited, and specified risk materials (SRM), such as brain and spinal cord, that are thought to contain the infectious agent of BSE, are removed and incinerated in slaughterhouses in many of the nations where BSE has been confirmed.

In Japan, the first occurrence of BSE was confirmed in September 2001. Since then, risk management measures in slaughterhouses have been implemented to test all cattle sent to slaughter for BSE, and the removal and incineration of SRM is undertaken. However, slaughtering processes is completed before the test results become available. This means that it is possible for scattered residues of SRM from BSE-infected cattle to contaminate sewage, resulting in the contamination of sewage sludge from the waste water treat-

\footnotetext{
* Correspondence to: Tsutsui, T., Applied Epidemiology Section, National Institute of Animal Health, 3-1-5, Kannondai, Tsukuba-shi, Ibaraki-ken, 305-0856, Japan.
}

ment facility in the slaughterhouse (slaughterhouse sludge) with the infectious agent. Given that a portion of the sludge is used to produce fertilizer, it became necessary to evaluate the risk of infection to cattle via the sludge-derived fertilizer.

Two methods are currently employed for the evaluation of risk, quantitatively and qualitatively. The former is a quantitative description of the degree of risk using probabilities of adverse events and damage assessments and is calculated empirically. The latter is a qualitative description of the degree of risk that is derived through analyzing various factors related to the risk. Since reliable information is required for all the necessary parameters with quantitative evaluations, qualitative evaluations are usually applied when available information is scarce. However, quantitative evaluations provide results that can be analyzed and interpreted more easily and permit objective estimations of extant effects and results of actions.

Qualitative evaluation of the risk from slaughterhouse sludge was performed by the Agence Française de Sécurité Sanitaire des Aliments (the French Agency of Sanitary Security of Food) and a quantitative evaluation was undertaken by Gale and Stanfield [1]. Quantitative evaluation of the risk of slaughterhouse wastewater to cattle has also been conducted by the Bureau of Rural Science (BRS) of the Australian Government Department of Agriculture, Fisheries and Forestry as a precautionary measure. However, no reports of risk evaluation on these issues have been undertaken to date in Japan.

This research aimed to evaluate the BSE infection risk associated with the utilization of slaughterhouse-sludge 
derived fertilizer in Japan. Analysis of the survey results regarding the slaughtering process, the system used to prevent the SRM contamination of sewage, and the handling of slaughterhouse sludge, was undertaken for this purpose. The risk of BSE infection was evaluated qualitatively using the results of these analyses before attempting a quantitative evaluation thereafter.

\section{MATERIALS AND METHODS}

The Ministry of Health, Labour, and Welfare of Japan (MHLW) conducted a survey on the operating procedures associated with processing cattle, such as pithing and splitting (the process of cutting a dressed carcass bilaterally along the axis of the vertebral column), for slaughterhouses across Japan in February 2003 and October 2004. However, the survey did not include any information regarding the systems required for the prevention of SRM contamination into sewage or the processes associated with the handling of slaughterhouse sludge. The Ministry of Agriculture, Forestry, and Fisheries (MAFF) therefore conducted a survey to assess the extant situation of slaughterhouse sludge utilization and handling. From October to November 2004, the questionnaire was mailed to 160 slaughterhouses engaged in slaughtering cattle from the relevant division at the Ministry. The questionnaire asked about the capacity of the facility, the measures to remove tissue particles in sewage and the use of sludge from wastewater treatment facility. Responses were received either by fax or mail from 126 slaughterhouses, giving us a return rate of $78 \%$. We processed and analyzed the responses and used the results to evaluate risk associated with slaughterhouse sludge.

First, we estimated the risk of BSE infection in cattle by slaughterhouse sludge qualitatively. A possible infection route for BSE was considered as being via ingestion of pasture soil to which BSE contaminated slaughterhouse-sludge fertilizer had been applied. According to this assumed route of infection, the expected reductions in the risk of infection at each stage were evaluated qualitatively. Quantitative analysis was conducted after assessing the qualitative results in order to evaluate the efficacy of the preventative measures. Specifically, in the quantitative analysis, the total risk of infection through the ingestion of slaughterhouse sludge derived from one BSE-infected cow slaughtered in Japan was determined using bovine oral $\mathrm{ID}_{50}$, the value of infectivity which will cause the $50 \%$ probability of infection to cattle through the oral route. Data processing, analysis and calculations were performed using Microsoft Excel (Microsoft Corp., Redmond, WA) and SPSS version 11 (SPSS Inc., Chicago, IL.).

\section{RESULTS}

We considered that the risk of BSE infection via sewage sludge was firstly generated by infectivity entering to wastewater at slaughterhouses. Then, the risk was reduced by measures taken at slaughterhouses and wastewater treat- ment facilities. The quantity of infectivity, to which cattle are exposed, is also considered to influence the overall risk of the BSE infection in Japan. The route of BSE infection to cattle via slaughterhouse sludge was estimated as shown in Fig. 1.

Possibility of SRM contamination of sewage at slaughterhouses: The results of the survey by MHLW reported that 154 of 160 slaughterhouses performed splitting on all or some of the cattle they processed. One hundred and seven of 163 slaughterhouses removed spinal cord before splitting carcasses using the suction apparatuses, and 15 slaughterhouses split carcasses off-center of the vertebral column. Since it is a common practice to use electric band saws in this process, it is quite possible that residues and spinal cord tissue are scattered on the floor in the process, even though the amount was reduced by the removal of spinal cord before splitting. It was also reported that the stunning process using stunning pistols and/or hammers was performed in all slaughterhouses and that 115 slaughterhouses $(82 \%$ in terms of the number of processed cattle) performed pithing. The risk of SRM contamination of sewage via effluent containing brain and spinal cord tissue as well as water used to clean equipment, while small, has been indicated.

According to the survey conducted by MAFF, 97 of 123 $(81 \%)$ have installed screens and/or filters at the inlets of their sewage drains to collect tissues derived from the splitting process before they flowed into the sewage (Table 1). Seventy-four \% of respondents (49/67) had installed filters and/or screens with mesh sizes of $2 \mathrm{~mm}$ or less. Sixty-nine $\%$ of respondents $(86 / 125)$ had installed screens or filters into the drains at more than one point, while 10 slaughterhouses $(5.4 \%)$ had not installed any filters.

Although contamination of sewage with the BSE infectivity was likely to occur, the MAFF survey revealed that many slaughterhouses dealt with tissue parts that should be prevented from entering the wastewater treatment facility by installing filters and/or screens. Mesh size for filters and screens used for the collection of tissue parts were usually (98\%) less than $6 \mathrm{~mm}$, the standard mesh size for filters set by the EU, meaning that the risk of SRM contaminating sewage is likely to be low. However, some slaughterhouses had not installed any filters/screens, or the filters/screens that had been installed had larger mesh sizes. In these instances the risk of SRM contamination of sewage via this route is therefore still a distinct possibility.

In the report on slaughterhouse sewage contamination in the United Kingdom, Gale and Stanfield [1] estimated that the risk posed by SRM contamination of sewage by tissue derived from stunning, pithing and splitting passing through 4-mm mesh filters installed along sewage drains was likely to be a maximum of $1 \%$ of the total SRM from one infected animal. While many slaughterhouses in Japan have removed spinal cord before splitting or installed filters into the drains with mesh sizes of $4 \mathrm{~mm}$ or less, the removal efficiency of these measures has not yet been clearly demonstrated. Consequently, for the quantitative evaluation of risk used in this study, the conservative figure of $1 \%$ of the SRM 


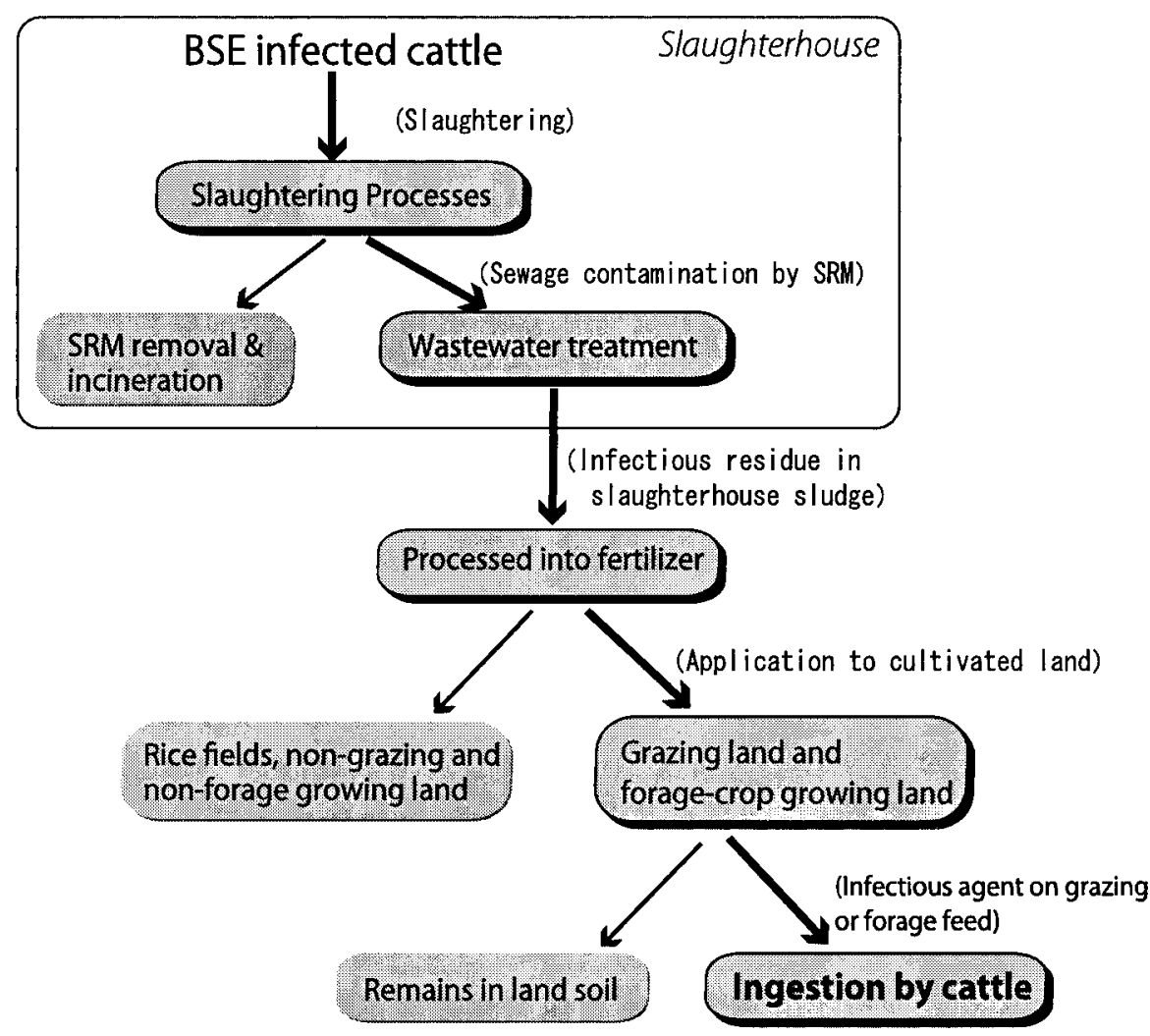

Fig. 1. Model structure.

Table 1. Installation of screens/filters for the collection of tissue derived from splitting (the process of bisecting the dressed carcass into right and left halves along the axis of the vertebral column) before such tissues enter the sewage drains

\begin{tabular}{lcccc}
\hline & \multicolumn{2}{c}{ Number of slaughterhouses } & \multicolumn{2}{c}{ Number of cattle processed } \\
\cline { 2 - 5 } & Facilities & Proportion & Cattle & Proportion \\
\hline With screens & 97 & $78.9 \%$ & 909,419 & $80.7 \%$ \\
Without screens & 26 & $21.1 \%$ & 218,138 & $19.3 \%$ \\
\hline Total & 123 & $100.0 \%$ & $1,127,557$ & $100.0 \%$ \\
\hline
\end{tabular}

from one infected animal was assumed to enter the sewage through filters/screens.

Possible reduction of BSE infectivity during wastewater treatment: Slaughterhouse sewage is generally treated using an activated sludge method in a wastewater treatment facility installed at the slaughterhouse. Before wastewater treatment by the activated sludge method, the precipitated sludge in the precipitation tank is removed and generally treated further by anaerobic fermentation. After aerobic treatment in an aeration tank, the supernatant is recycled, leaving the microbe-rich sludge (excess sludge). The sludge is removed from the system and finally, it is incinerated, buried or processed to fertilizer.

While the BSE infectivity may be reduced by the microbial decomposition associated with wastewater and sludge treatment, no such studies have been published to date. In addition, abnormal prion proteins are generally thought to be highly resistant to proteinases and heat treatment. Consequently, in our quantitative evaluation, we assumed that a reduction in the BSE infectivity was not likely under these conditions, although a reduction in BSE infectivity may have accompanied the physical dilution and dispersal of the effluent with each treatment.

Possibility of using sludge-derived fertilizer on grazing land and forage-crop growing land: The survey conducted by MAFF, revealed that almost half of the slaughterhouses (64 out of 120) incinerated the sludge. The destination of the remaining sludge was principally to crop fields (20 out of 26) and utilization of the sludge for grazing land and/or forage-crop growing land was not confirmed. 
For the quantitative risk evaluation, a worst-case scenario was adopted in which it was assumed that all of the sludge from a slaughterhouse was processed into fertilizer. As there was no detailed data available regarding the distribution of sludge-derived fertilizer, it was assumed that the proportion of sludge applied to grazing land and forage-crop growing land was the same for the proportion of the entire grazing and forage-crop growing area $\left(9.3 \times 10^{3} \mathrm{~km}^{2}\right.$, MAFF Statistics, 2003) to all farming area $\left(4.4 \times 10^{4} \mathrm{~km}^{2}\right.$ including $1.7 \times 10^{4} \mathrm{~km}^{2}$ of rice fields, MAFF Statistics, 2003 ) in Japan. Since the amount of fertilizer applied to rice fields was estimated to be approximately 0.3 times of that applied to other crop fields [3], the amount of the sludgederived fertilizer used in the farming fields was calculated by weighting the amount applied to the rice fields by 0.3 . Based on these values, it was estimated that $28 \%$ of the sludge-derived fertilizer produced was applied to grazing land and forage-crop growing land.

Possibility of ingestion of sludge-derived fertilizer applied to grazing land and forage-crop growing land: The fertilizer applied to grazing land and forage-crop growing land is mixed into the land soil, and depending on the condition of the land, occurs at varying concentrations in the soil. Generally, fertilizer is mixed with soil to a depth of 20-30 $\mathrm{cm}$ for developing cultivated lands, and sprayed on the surface of existing cultivated land. Although there was no data regarding the amount of sludge-derived fertilizer applied to a unit area of land, it is likely that fertilizer was diluted considerably due to mixing and permeation into the soil of the land. If BSE-infected sludge-derived fertilizer was applied to grazing land and forage-crop growing land, the possible routes of infection would include direct ingestion of contaminated soil from the ground by grazing cattle and ingestion of soil attached to the forage by stall-fed cattle. A study assessing the amount of soil ingested by cattle using Scandium $(\mathrm{Sc})$ as an indicator reported that a single cow ingested $0.1 \mathrm{~kg}$ per day in the field and approximately $1 / 3$ of that in under stall-fed conditions [2]. Assuming an average of 173 grazing days per year, the total population of grazing and stall-fed cattle per year was estimated at approximately 8.7 $\times 10^{4}$ cattle and $4.4 \times 10^{6}$ cattle, respectively. Stall-fed cattle are also fed imported forage with the ratio of domestic forage being estimated at approximately $70 \%$. Taken together, the possibility of ingesting sludge-derived fertilizer by cattle was thought to be very low considering the extent of dilution of the fertilizer and soil from the land, the relatively limited amount of soil ingested by cattle compared to the mass of soil in the field, the low ratio of grazing cattle that ingest large amounts of land soil, and the feeding of imported herbage to stall-fed cattle.

The quantitative evaluation of risk based on the limited data was performed on the assumption that all of the forage from grazing land and forage-crop growing land $\left(9.3 \times 10^{4}\right.$ $\mathrm{km}^{2}$ ) was fed to cattle. It was further assumed that the fertilizer that was applied to the ground was mixed with ground soil to an average depth of $5 \mathrm{~cm}$; the depth attributed to permeation of the fertilizer into the soil after application. The specific gravity of common soil was reported to be approximately 1.0 [4], which implies that the total amount of soil dedicated to the cultivation of forage crops to which sludgederived fertilizer may have been applied was approximately $4.6 \times 10^{8}$ tons. It was also assumed that an average of $0.1 \mathrm{~kg}$ of soil was ingested by one grazing cow per day, and 1/3 of that was ingested by one stall-fed cow. Based on the aforementioned data, the total amount of soil ingested by all of the cattle in Japan was calculated to be approximately $1.2 \times$ $10^{5}$ tons per year. Thus, based on the assumption that the soil ingested by cattle occurred was within $5 \mathrm{~cm}$ of the surface, the total amount of soil ingested by cattle was estimated to be $0.026 \%$ of the $4.6 \times 10^{8}$ tons of soil under grazing or cultivation with forage crops.

Summary of risk evaluation: Although the possibility of sewage contamination by SRM in the processes associated with abattoir processing, such as through splitting and pithing, is thought to exist at many slaughterhouses, the actual level of contamination in many instances was relatively low due to the installation of filter(s) at the drains to the wastewater treatment facilities. In addition, it has been demonstrated that sludge-derived fertilizer would have been diluted by mixing with ground soil and that the amount of soil ingested by cattle would be small compared to the total amount of the ground soil. The possibility of cattle ingesting sludge-derived fertilizer is therefore considered to be very low. This was also described by the results of the quantitative evaluation. The total BSE infectivity attributed to SRM risk per head of infected cattle with clinical symptoms was taken to be $7,500 \mathrm{ID}_{50}\left(\right.$ Bovine oral $\left.\mathrm{ID}_{50}\right)$ based on an infectious value of $10 \mathrm{ID}_{50}$ per SRM $1 \mathrm{~g}$ and an average brain and spinal cord mass per head for cattle being $750 \mathrm{~g}$ (Scientific Steering Committee, 1999). The quantitative risk levels for each processing step were estimated as follows (Fig. 2): 1) 1\% of the infectivity of one head of infected cattle contaminated slaughterhouse sewage, 2) the infectivity was not reduced by sludge treatment, 3) $28 \%$ of the sludge was applied to grazing land and forage-crop growing land as sludge-derived fertilizer, and 4) $0.026 \%$ of the sludge-derived fertilizer was ingested by cattle. In a worstcase scenario in which one infected head of cattle with clinical symptoms was processed in a slaughterhouse, the total BSE infectivity ingested by cattle in Japan was calculated by multiplying the factors mentioned above, and estimated to be $5.5 \times 10^{-3} \mathrm{ID}_{50}$ per year.

\section{DISCUSSION}

This study evaluated the risk of BSE infection in domestic cattle via fertilizer processed from sewage sludge from wastewater treatment facility in the slaughterhouse (slaughterhouse sludge-derived fertilizer) when a head of BSEinfected cattle was slaughtered using both qualitative and quantitative techniques to analyze survey results and various statistical data available.

Qualitative analysis indicated that sewage contamination by SRM associated with splitting, pithing, and stunning 


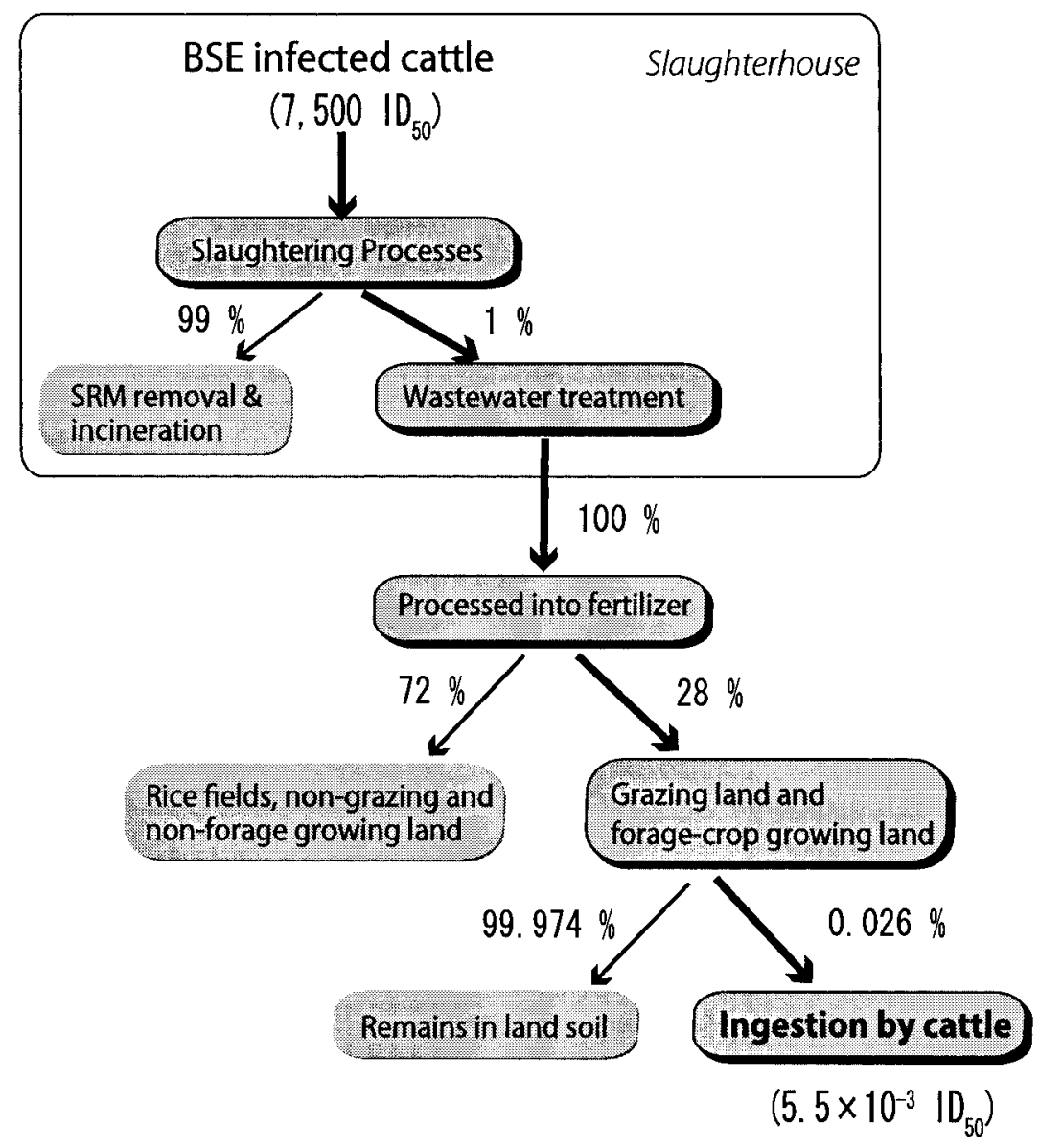

Fig. 2 Summary of quantitative risk assessment.

using pistols and hammers was quite possible. However, dilution of sludge-derived fertilizer by ground soil and the small amount of soil ingested by cattle while eating resulted in a very slight probability of ingesting sludge-derived fertilizer. Given this decrease in infectivity due to dilution of sludge-derived fertilizer in the ground soil, combined with the application of fertilizer to the lands other than grazing land and forage-crop growing land, quantitative analysis indicated that the total infectivity ingested by cattle in Japan was $5.5 \times 10^{-3} \mathrm{ID}_{50}$.

Assuming that all of the sludge-derived fertilizer was applied to grazing land and forage-crop growing land, the infectious value ingested by cattle would increase by a factor of 3.6 , the inverse number of $28 \%$. In the three years from October 2001 to September 2004, 11 BSE-infected cattle have been diagnosed using the BSE test at slaughterhouses in Japan. Consequently, if four infected cattle were processed per year, the infectious value would be four times higher than that calculated above. In the event that a large SRM tissue sample with a high infectivity was not diluted during the process and then subsequently ingested by cattle, it is possible that these cattle would become infected with
BSE. Although these factors increase the risk of BSE infection, the possibility of a BSE epidemic extending in Japan via this infection route is considered to be very low.

Results indicated that replacing the current slaughter methods, such as pithing and splitting, with other methods combined with the removal of residues from drain water would be effective in achieving an overall reduction in the infectious risk of BSE through sewage contamination by SRM. The risk from slaughterhouse sludge was considered to arise mainly from the application of sludge-derived fertilizer to grazing land and forage-crop growing land. Consequently, preventing the application of the sludge-derived fertilizer on these lands would considerably reduce this risk.

AFSSA published a report on the risk of water and soil contamination by abnormal prion proteins derived from slaughterhouse sewage and sludge in September 2003. The report suggested that the contamination risk of sewage by SRM during processes such as stunning, pithing, and splitting, based on the results of the survey regarding the slaughtering process in slaughterhouses, was possible. They conducted an experiment to determine the level of SRM in sewage using glial fibrillary acidic protein (GFAP) as it is 
specifically expressed in the central nervous system. However, they stated that results of the experiment not suited for the reliable assessment of the risk. The authors concluded that, although they recognized the potential for risk of BSE infection via sludge-derived fertilizer, scientific data in support of the hypothesis was insufficient. Gale and Stanfield [1] conducted quantitative evaluations of the risk of BSE infection in humans and cattle via sludge-derived fertilizer route in the United Kingdom. They estimated that the BSE infectious value ingested by one head of cattle per year was $7.07 \times 10^{-4}$ bovine oral $\mathrm{ID}_{50}$, when the sludge from 700,000 cattle, including 3,780 infected cattle was applied to pastureland per year and implied that 49.5 cattle per year could become infected by BSE. The number of infected cattle processed at abattoirs was estimated to be 3,780, while the number of cattle infected via sludge containing infectious BSE tissue was estimated to be a maximum of 50. Therefore, these authors concluded that application of sewage sludge on land is not sufficient to sustain the BSE epidemic in the UK cattle herd.

Several similarities were observed in the reports evaluating the risk of contracting BSE via slaughterhouse sludge and sludge-derived fertilizer. One difficulty related to quantitative estimations of BSE infection due to SRM contamination of sewage is estimating the amount of SRM that comes into contact with sewage. This in turn is related to difficulties associated with measuring the amount of SRM that could pass through the filters of the sewage route. Another difficulty is assessing the extent of slaughterhouse sludge ingestion by cattle, which has never been confirmed. Further investigations of these difficulties are required to obtain more accurate risk evaluation and to overcome the associated problems.

This primarily qualitative study analyzed the results of a survey undertaken by MAFF with the aim of developing a practical model for evaluating the risk of BSE infection to cattle via slaughterhouse sludge-derived fertilizer. Based on the results of this qualitative evaluation, the risk of BSE infection in cattle was then assessed quantitatively. While several areas of these assessments require further investigation, the level of BSE infection risk via slaughterhouse sludge was estimated to be low. It is thought that this report should serve as a useful reference for further research on inclusive risk assessments for BSE transmission to cattle via SRM contamination of sewage.

ACKNOWLEDGEMENTS. The author is grateful to Food Safety and Consumer Affairs Bureau, Ministry of Agriculture, Forestry and Fisheries of Japan and numerous colleagues for their cooperation with the collection of data and information.

\section{REFERENCES}

1. Gale, P. and Stanfield, G. 2001. Towards a quantitative risk assessment for BSE in sewage sludge. J. Appl. Microbiol. 91: 563-569.

2. Koyama, Y., Miyamoto, S., Sudo, M., Kikuchi, T., Takahashi, M. and Kyuma, T. 1985. Estimation of the amount of soil consumed by cattle using Scandium (Sc) as an indicator and discussion on its meaning. Jpn. J. Soil Sci. Plant Nutr. 56: 269273(in Japanese).

3. MAFF. 2000. Research on the Environment of Agricultural Production (in Japanese).

4. Mitsui, S. 1976. p. 64. Saishin Dojyo, Hiryo, Shokubutu Eiyou Jiten Hakubun-sha. Tokyo (in Japanese).

5. Prusiner, S.B. 1998. Prions. Proc. Natl. Acad. Sci. U.S.A. 95: 13363-13383.

6. Wilesmith, J.W., Wells, G.A., Cranwell, M.P. and Ryan, J.B. 1988. Bovine spongiform encephalopathy: epidemiological studies. Vet. Rec. 123: 638-644. 